\title{
An Exploratory Study of the Relationship between Alcohol Use and Sexual Risk Behaviour among Students at the University of Kwazulu-Natal
} Mutinta Given*

UKZN, Durban, KwaZulu-Natal South Africa

\begin{abstract}
Background: The prevalence of sexual risk behaviour among South African university students is high. Alcohol consumption has been identified as one of the underlying factors to students' sexual risk behaviour. There is a dearth of studies conducted on the relationship between students' alcohol use and sexual risk behaviour. The aim of this study is to investigate the relationship between alcohol use and sexual risk behaviour among sexually active students at the University of KwaZulu-Natal.
\end{abstract}

Methods: The study was underpinned by a quantitative research paradigm. A questionnaire designed to be completed by students without the intervention of the researcher was used. In the questionnaire, alcohol use was measured as use over the previous six months compared with instances related to engaging in penetrative sex and on the most recent incident of penetrative sex. In the context of this study, the concept sexual risk behaviour is used to imply not using condoms in the past six months with a new partner or having multiple sexual partners. The relationship between students' alcohol use and sexual risk behaviour was determined by performing bivariate and multiple logistic regressions.

Results: There was statistical significant relationship between alcohol use and having multiple sexual partners among female and male students. Among males, failure to use condoms consistently with new partners was significant. This phenomenon was common among male students who frequently used alcohol in relation to engaging in penetrative sex (OR $0.74 ; \mathrm{Cl}, 0.00-2.07)$. Though there was no statistical significance, findings reveal that the risk of not using condom with new partners was twice higher among female students in particular among females who frequently used alcohol in relation to engaging in penetrative sex.

Conclusion: Findings in this study are in agreement with, and build on previous studies that related alcohol use to having multiple sexual partners. Failure to use condoms consistently was related to consuming alcohol in relation to engaging in penetrative sex. This experience was common both among female and male students who frequently used alcohol in relation to engaging in penetrative sex.

Keywords: Alcohol Consumption; Sexual Risk Behaviour; University Students; HIV and South Africa

\section{Background}

The Human Immunodeficiency Virus infection and Acquired Immunodeficiency Syndrome (HIV and AIDS) remain huge worldwide health problems with unparalleled effects. More than half of the current new infections worldwide take place among young people aged between 12 and 24 years [1].

In 2014, about 35.3 million people worldwide were living with HIV, with approximately 2.3 million new infections worldwide [1]. There are 75 million people infected with HIV since the start of the epidemic, and 1.6 million people in 2013 died from AIDS related causes worldwide [2].

Sub-Saharan Africa in particular South Africa is one of the worst hit by the HIV and AIDS scourge than any other region in the world. However, in the past decade South Africa made significant progress in turning the HIV epidemic tide [2]. By 2008, South Africa started to experience a decline in HIV incidence among young age groups [3]. To this day, evidence-based interventions focused on HIV prevention, treatment, care, support have been implemented with some success. The National Department of Health and the South African National AIDS Council (SANAC) say that the prevalence of HIV has remained high but stable over the past ten years [4]. The number of people on Anti-Retroviral Therapy (ART) has increased to 2.4 million which has resulted in the significant decrease in AIDS mortality and increase in life expectancy [5].
As in other parts of the world, young people are among the most affected population. Young people in South Africa show a high prevalence of sexual risk behaviour. Besides, majority of young people seem to start their sexual debut early and are likely to engage in sexual risk behaviour including multiple and concurrent sexual partnerships, and unprotected sex [6].

The Higher Education HIV/AIDS Programme (HEAIDS) conducted a survey among 23 institutions of higher learning in South Africa and reported that the HIV prevalence to be at $6 \%$ lower than the national average [7]. Further, the survey revealed that the prevalence of sexual risk behaviour was $68 \%$, which was slightly lower than estimated national average [7]. Studies indicate that students engage in all sorts of risk behaviour including one night stands, multiple and concurrent sexual partnerships, intergenerational sex, age-disparity, coercive sex, and open sexual relationship [6,8]. Studies show that alcohol

*Corresponding author: Mutinta Given, UKZN, Heard, University Road, Durban, KwaZulu-Natal 4001, South Africa, Tel:+27733330667; E-mail: mutinta@ukzn.ac.za

Received October 29, 2014; Accepted December 27, 2014; Published January 07, 2014

Citation: Given M (2014)An Exploratory Study of the Relationship between Alcoho Use and Sexual Risk Behaviour among Students at the University of KwazuluNatal. J AIDS Clin Res 6: 412. doi:10.4172/2155-6113.1000412

Copyright: ( 2014 Given M, et al. This is an open-access article distributed under the terms of the Creative Commons Attribution License, which permits unrestricted use, distribution, and reproduction in any medium, provided the original author and source are credited. 
consumption is one of the main underlying factors to students' sexual risk behaviour $[8,9]$.

The latest World Health Organisation (WHO) report on global status on alcohol and health indicate that South Africa is one of the countries in Africa with a high per capital recorded at $15+$ for the period $1961-2010$ [10]. Beer is the most used reported at $48 \%$ followed by wine at $18 \%$ and spirits at $16 \%$ [10]. Students in South African universities seem to follow the same pattern as far as alcohol use is concerned.

A study found that half of the students had drunk alcohol in the last twelve months and $24 \%$ had engaged in excessive episodic drinking [7]. The same study also reported that students had easy access to alcohol and engaged in heavy drinking during their social events [7].

HEAIDS report indicates that alcohol use was one of the principal factors that influenced students' problems on campuses including violence, academic performance, rape, and mental health [7]. Students who drunk heavily were more likely to engage multiple and concurrent sexual partnerships when they were compared to students who did not drink heavily $[11,12]$. Literature also shows that young people with severe mental illness who engaged in sexual risk behaviour in the past twelve months were more likely to have an alcohol disorder than were participants who did engage in sexual risk behaviour [11]. Other studies associate a history of problem drinking to treatment for sexually transmitted diseases [13] and that alcoholics in treatment are more likely to engage in sexual risk behaviour than the general population $[11,14]$.

The alcohol myopia model explains that alcohol has influence on human social behaviour. The alcohol myopia model states that alcohol reduces cognitive capacity and causes people to focus cues that are most salient in the environment [14]. Less salient cues require additional cognitive resources to process and are, therefore, less likely to be acted upon by an intoxicated person [14]. In addition, the effects of alcohol on cognition are proposed to be linear; the more intoxicated a person is, the more pronounced the myopia becomes [15]. In sexual events, the most salient cues are usually those that involve intimacy and immediate pleasure of the sexual contact more abstract or distal cues, such as suspicion that the sexual partner could be HIV infected, or HIV prevention messages read heard on television, are less salient and require addition cognitive resources to process. Therefore, when intoxicated the ability to consider these distal, inhibitory cues decreases and protective behaviour is less likely to be enacted [14].

The expectancy theory explains that that there is a link between alcohol consumption and sexual risk behaviour [14]. The theory focuses on the importance of internalised cultural and social expectations about the effects of substances on sexual behaviour [14]. In the expectancy theory, people's expectations that substance use lowers sexual inhibitions and/or enhances sexual pleasure moderates their sexual behaviour, making sexual behaviour under the influence more likely and more risky as such expectations increase [14]. For example, studies show that individuals who drink report beliefs that alcohol reduces sexual inhibitions [15], helps them feel more open to other people [16], and enhances sexual pleasure $[14,17]$. There is evidence that expectancies alone, even in the absence of actual alcohol consumption, are enough to change people's behavioural intentions. For example, in a balanced placebo study, individuals who believed they had consumed alcohol, but who had actually consumed a placebo drink, reported stronger intentions to engage in unsafe sex and lower perceptions of risk when compared to those who consumed a placebo and did not believe they were drinking alcohol [14]. A study on Men who have sex with men found that those who reported unprotected sex more strongly believed in the sexual effects of substances, when compared to men who did not engage in unprotected sex [18].

A study hypothesized that constantly avoiding sexual risk becomes cognitively burdensome, motivating a behavioural rebound that allows individuals to escape from this constraint [14]. The escape model explains that constant thought suppression regarding desire to engage in sexual risk behaviour predicts unsafe sexual encounters occurring through public venues. As such, cognitive restraint or burden is considered vulnerability in the escape model [14]. Besides, the study hypothesizes that, cognitive restraint, when combined with specific expectancies or personality dispositions, lead people to use substances strategically to induce a state of cognitive escape regarding personal risk $[14,19]$. The argument of the study is that substance use is a strategy used to facilitate cognitive escape and facilitates general cognitive disengagement, wherein people are more sensitive to external pressures [14]. For example, research shows that the association between substance use and unsafe sex was stronger among men who scored higher on a measure of effortful sexual restraint when compared to men whose scores reflected less effortful adherence to safer sex norms $[15,16]$. Literature review revealed that gay men who both frequently used drugs and strongly expected that alcohol and drugs facilitated cognitive escape, reported more sexual risk behaviour than those with weaker expectancies [17-25].

Evidence on the influence of alcohol use is widespread. However, the problem of alcohol consumption and sexual risk-taking behaviour among students has not been specifically addressed. Therefore, the researcher deemed it crucial to explore and gain understanding of the link between alcohol and sexual risk behaviour.

Thus, the main aim of this article is to examine the relationship between alcohol consumption and sexual risk-taking behaviour among students at the University of KwaZulu-Natal.

\section{Methods}

A study was conducted at the University of KwaZulu-Natal, Westville Campus, in South Africa. The University of KwaZulu-Natal is located in KwaZulu-Natal Province a hub of the HIV epidemic in South Africa, with HIV prevalence at $17.8 \%$ (UNAIDS 2010). This province has the second largest provincial population (10.8 million) and is one of the poorest provinces in the country (Statistics South Africa, 2012). UKZN was formed in 2004 following the merger of the University of Natal and the University of Durban-Westville. It has five campuses: Howard College, Westville, Pietermaritzburg, Edgewood, and the Nelson Mandela Medical School, and enrols about 40000 students. The demographics of the campuses vary. The campuses are multicultural, comprised of black, Indian, coloured and white students, with students coming from within South Africa, other African countries, and other continents. Some students live on campus and others live in rented houses off-campus, often in neighbourhoods that are closely joined, with varying mixes of racial groups. One of the five campuses and one of the four colleges at Westville campus were purposively selected for the study as financial and technical constraints made it impossible to cover all the campuses. Registered undergraduate students in the College of Law and Management Studies in particular in the School of Accounting, Economics and Finance were invited to participate. Out of 1,164 registered undergraduate students at the College, 589 completed the survey. The response rate was $76 \%$. The survey used a questionnaire that had several items including alcohol and drug use, self-rated health in general and mental health, sexual relationships, and sexuality. The 
questionnaire also had questions on social and demographic features in particular questions on religious affiliation, level of study, age, area of growing up and sex. The questionnaire was developed by the researcher in 2013 based on existing questionnaires on students' sexual risk behaviour and alcohol use.

Data for this study was collected in a lecture theatre at Westville campus, with the researcher present to attend to queries during the process of filling the questionnaire. The distribution of the questionnaire was preceded by the circulation of the consent form describing the purpose of the study. With adequate knowledge of the study students were asked to sign the form if they wanted to participate. Students were told that participation was voluntary and were free to discontinue at any given time without any consequences. Privacy, anonymity, and confidentiality were assured and upheld. The contact details of the researcher and research office were provided in case students had specific questions. The University of KwaZulu-Natal Research Ethics Committee provided permission to conduct the study while the Office of the Registrar provided the gatekeeper's letter.

\section{Measurements}

Social demographic variables: In this study, age was presented as $>21$ years. The median in the study sample distribution determined the age cut-off. Students were asked the role religion played in their families when growing up and two options were provided. The first option was that religion played an important role and second that religion was somehow important when growing up were coded that religion had an important role when growing up. Answers that religion was not important and religion was not important all were coded that religion had a minor role when growing up. Students were also asked where they grew up; either rural or urban or peri-urban. The variable was in two parts combining peri-urban and urban into a single category and rural into a separate category dividing the variable into two parts.

\section{Variable associated to alcohol}

Alcohol as related to sexual behaviour: Students were asked how often they used alcohol before engaging in sexual intercourse. They were five options given to students; always, over $49 \%$ of the time, about $49 \%$ of the time, less than $24 \%$ of the time, and never. This variable was divided into two parts by joining the first three options to form a variable 'alcohol used in relation to sexual behaviour'. The last two options were combined and read as 'non-use of alcohol in relation to sexual behaviour'.

Alcohol use on the last event of penetrative sex and in the past six months: Students were asked if they drunk alcohol the last time they had penetrative sex. They were two options; yes or no. The first variable related to alcohol was alcohol use in the past six months underpinned by the question on how often students used alcohol during the past six months. There were five responses to this question; four times a week, two to four times a week, three to four times a month, once a month, and never. Answers one to three were coded as frequent alcohol use while the fourth answer was categorised as rare alcohol use. The fifth answer was categorised as abstainers.

\section{Effect variables associated to sexual behaviour}

Inconsistent condom use with a new partner and multiple sexual partnerships: To achieve the research objective on inconsistent condom use with a new partner, students were asked how often they used a condom with new sexual partners. They were five options; 'always', 'often', 'sometimes', 'never', and 'the question does not apply'. The options were then divided into two parts. Consistent condom use with a new partner was categorised for students who answered 'always'. Students who gave other options were categorized as inconsistent condom use. To achieve the objective multiple sexual partnerships students were asked to relate the number of sexual partners they had in the last six months. This question was later divided into two parts and read as 'fewer than two' or 'two or more sexual partners'. The latter was categorized as having 'many sexual partnerships'. The selection of outcome variables and cut-off points within them was based on national indicators previously used in HIV and AIDS studies in South Africa [3].

\section{Data analysis}

Data was analysed using the Statistical Package for the Social Sciences (SPSS) version 19.0. The confidence interval was $94 \%$. Chisquare tests were performed to examine differences in the proportions of males and females for both dependent and independent variables. Bivariate and multivariate logistic regression analyses were performed to assess the associations between alcohol use and sexual risk behaviour variables. The confounders in the study were chosen based on the literature reviewed on South Africa. The same confounders were used to analyze the association between different alcohol exposure variables and both outcomes of sexual risk behaviour used in the study. Separate analyses were performed for males and females to detect gender patterns in the associations. The missing values represent individuals who gave incomplete answers for one of the variables included in the multivariable logistic regression analysis. Cases for missing values were not included in the logistic regression analysis.

\section{Findings}

Findings reveal that the frequency of using alcohol in the past six months was common among male students. Among male students who were using alcohol, nearly $26 \%$ had used alcohol when they had penetrative sex. There was a significant difference between male and female students who were engaging in sexual intercourse after consuming alcohol. Out of the total respondents in this study, $32 \%$ of the students reported that they had multiple sexual partnerships in the last six months. The practice of having multiple sexual partnerships was more widespread among male than female students. Approximately $36 \%$ of male students reported that they did no use condoms consistently with new partners. This practice was significantly high among female students as $49 \%$ reported the same behaviour. Table 1 presents both male and female students patterns of alcohol consumption and their sexual behaviour.

Findings on students' alcohol consumption in the last six months in relation to engaging in sexual intercourse and consumption of alcohol on the last incident of sexual intercourse was related to having multiple sexual partnerships. Students who frequently used alcohol in relation to engaging in sexual intercourse were 0.4 -fold higher risk of engaging in sexual intercourse with new partners (OR, 0.63; CI, 0.04-1.56).

When the analysis on students who frequently used alcohol in the last 6 months was adjusted, findings reveal that both males and (OR, 2.54; CI, 1.11-4.95) and females (OR, 3.07; CI, 0.76-8.40) may have been at risk of having had more than two multiple sexual partners during the last 6 months than students who were not using alcohol.

When the adjustment was made for confounders, female (OR, 1.34; $\mathrm{CI}, 0.8-5.07)$ and male students (OR, $0.74 \mathrm{CI}, 0.00-2.07)$ who frequently used alcohol in relation to having sexual intercourse were reported to may have been at risk of not using condom with new partners. Table 2 
Citation: Given M (2014) An Exploratory Study of the Relationship between Alcohol Use and Sexual Risk Behaviour among Students at the University of Kwazulu-Natal. J AIDS Clin Res 6: 412. doi:10.4172/2155-6113.1000412

Page 4 of 6

reveals the relationships between alcohol use in relation to sexual risk behaviour among students.

Findings in table 3 further show that both females (OR, 4.46; CI, 29-11.96) and male students (OR, 1.51; CI, 0.47-3.29) who had taken alcohol the previous six month had multiple and concurrent sexual partnerships.

\section{Discussion}

The study shows a higher number of students using alcohol associated to engaging in sexual risk behaviour. The study is consistent with another study in South Africa that reported a higher number of male students more likely than females to consume more alcohol before engaging in sexual intercourse [21]. This study shows that there

\begin{tabular}{|c|c|c|c|c|c|}
\hline \multirow[t]{2}{*}{ Measurable Characteristics } & Attributes & $\begin{array}{c}\text { All } \\
(\mathrm{N}=1179)\end{array}$ & $\begin{array}{c}\text { Males } \\
(\mathrm{N}=693)\end{array}$ & $\begin{array}{l}\text { Females } \\
(\mathrm{N}=486)\end{array}$ & Chi-Square \\
\hline & & $\mathbf{N}(\%)$ & $\mathbf{N}(\%)$ & $\mathbf{N}(\%)$ & (P-VALUE) \\
\hline Age & Less than or equal to 21 years & $304(50.5)$ & $196(56.9)$ & $107(43.0)$ & $<.002$ \\
\hline \multirow[t]{4}{*}{$\begin{array}{l}\text { Number of sexual partners in the } \\
\text { past } 6 \text { months }\end{array}$} & $0-1$ sexual partner in the past 6 months & $340(65.3)$ & $178(57.4)$ & $162(76.4)$ & $<.002$ \\
\hline & more than 2 sexual partners in the past 6 months & $172(32.5)$ & $125(40.2)$ & $47(21.3)$ & \\
\hline & Missing & 77 & 43 & 34 & \\
\hline & Older (> 21 years) & $240(47.3)$ & $150(42.0)$ & $135(55.0)$ & \\
\hline \multirow[t]{3}{*}{$\begin{array}{l}\text { Alcohol use at most recent incident of } \\
\text { penetrative sex* }\end{array}$} & $\begin{array}{c}\text { Non-Use of alcohol at most recent incident of } \\
\text { penetrative sex }\end{array}$ & $180(71.8)$ & $113(69.6)$ & $66(75.8)$ & .002 \\
\hline & $\begin{array}{l}\text { Use of alcohol at most recent incident of penetrative } \\
\text { sex }\end{array}$ & $67(26.0)$ & $47(28.2)$ & $20(22.0)$ & \\
\hline & Missing & 48 & 33 & 14 & \\
\hline \multirow[t]{2}{*}{ Influence of religion in students life } & Major influence of religion & $368(61.4)$ & $201(57.1)$ & $167(67.4)$ & $<.002$ \\
\hline & Minor influence of religion & $221(36.4)$ & $144(40.7)$ & $77(30.4)$ & \\
\hline \multirow[t]{3}{*}{ Condom use with new partner } & Consistent use of condom with new partner & $201(56.7)$ & $193(61.5)$ & $206(49.7)$ & $<.002$ \\
\hline & Inconsistent condom use with new partner & $220(41.1)$ & $115(36.3)$ & $104(48.1)$ & \\
\hline & Missing & 68 & 37 & 30 & \\
\hline \multirow[t]{3}{*}{ Locale of growing up } & Urban & $305(50.6)$ & $169(47.7)$ & $136(55.0)$ & .010 \\
\hline & Rural & $284(47.2)$ & $177(50.1)$ & $107(43.0)$ & \\
\hline & Missing & 34 & 12 & 22 & \\
\hline \multirow[t]{3}{*}{$\begin{array}{l}\text { Alcohol use with regard to sexual } \\
\text { activity }{ }^{*}\end{array}$} & Non-Use of alcohol in relation to sexual activity & $195(79)$ & $122(75.5)$ & $146(82.3)$ & .003 \\
\hline & Use of alcohol in relation to sexual activity & $52(21)$ & $37(22.3)$ & $19(15.5)$ & \\
\hline & Missing & 47 & 24 & 13 & \\
\hline \multirow[t]{3}{*}{ Alcohol use in the last 6 months } & Refrainers of alcohol & $260(45.7)$ & $140(40.8)$ & $120(53.2)$ & $<.002$ \\
\hline & Rare users of alcohol in the past 6 months & $225(39.4)$ & $143(42)$ & $81(35.8)$ & \\
\hline & Regular users of alcohol in the past 6 months & $70(11.5)$ & $50(14.0)$ & $19(7.7)$ & \\
\hline
\end{tabular}

${ }^{*}$ Respondents who refrained from alcohol in the last 6 months were excluded from data analysis.

Table 1: chi-square test findings for both male and female differences across different sociodemographic characteristics.

Characteristics

\begin{tabular}{|c|}
\hline Characteristics \\
\hline Non-Use of alcohol with respect to sexual activity \\
\hline Use of alcohol with regard to sexual activity \\
\hline Older and more than 21 years \\
\hline Living in a rural area while growing up \\
\hline Minor influence of religion while growing up \\
\hline
\end{tabular}

Multiple Sexual Partnerships

All

Females

1 (ref)

$3.17(2.50-7.00)$

$4.64(1.08-14.22)$

$0.01(.49-1.13)$

$0.00(.67-0.54) \quad 0.31(.63-1.79)$

$0.50(.72-2.13)$
Inconsistent Condom Use With New Partner

\begin{tabular}{l|l|l} 
All & Females & Males
\end{tabular}

1 (ref)

1 (ref)

1 (ref)

1 (ref)

$1.34(.90-5.07) \quad 0.74(0.00-2.07)$

\begin{tabular}{|c|c|c|c|}
\hline $89(.53-0.46)$ & $0.31(.89-0.95)$ & $0.57(.80-2.07)$ & $0.11(.67-0.85)$
\end{tabular}

\begin{tabular}{|l|l|l|l}
$.83(.51-0.36)$ & $1.17(0.46-2.24)$ & $1.67(0.32-4.39)$ & $1.19(0.33-2.59)$
\end{tabular}

$0.47(.89-1.41)$

$.97(.64-0.43)$

$0.04(.53-1.04)$

$00(.60-0.64)$

${ }^{*}$ Respondents who refrained from alcohol in the last 6 months were excluded from data analysis.

Table 2: multivariate associations between sociodemographic factors and the use of alcohol in relation to sexual activity with sexual risk behaviour.

\begin{tabular}{|c|c|c|c|c|c|c|}
\hline \multirow[t]{2}{*}{ Characteristics } & \multicolumn{3}{|c|}{ Multiple Sexual Partnerships } & \multicolumn{3}{|c|}{ Inconsistent Condom Use With New Partner } \\
\hline & All & Females & Males & All & Females & Males \\
\hline $\begin{array}{l}\text { Non-Use of alcohol at the most recent incident } \\
\text { of penetrative sex }\end{array}$ & 1 (ref) & 1 (ref) & 1 (ref) & 1 (ref) & 1 (ref) & 1 (ref) \\
\hline $\begin{array}{l}\text { Use of alcohol at the most recent incident of } \\
\text { sexual intercourse }\end{array}$ & $4.24(1.06-4.9)$ & $4.46(2.30-11.96)$ & $1.51(0.47-3.29)$ & $0.49(.97-1.31)$ & $1.24(.98-4.04)$ & $0.34(.79-1.26)$ \\
\hline Older or greater than 21 years & $.87(.58-0.31)$ & $.93(.44-1.00)$ & $.87(.53-0.44)$ & $0.46(.96-1.12)$ & $0.74(.89-2.43)$ & $0.17(.70-0.94)$ \\
\hline Living in a rural area while growing up & $.98(.65-0.47)$ & $0.55(.71-1.41)$ & $.76(.45-0.21)$ & $1.03(0.39-2.01)$ & $1.56(0.27-4.14)$ & $0.96(0.19-2.19)$ \\
\hline Minor influence of religion while growing up & $0.63(1.08-1.41)$ & $0.69(.79-2.65)$ & $0.57(.96-1.57)$ & $0.01(.68-0.49)$ & $.93(.47-0.84)$ & $0.12(.69-0.84)$ \\
\hline
\end{tabular}

${ }^{*}$ Respondents who refrained from alcohol in the last 6 months were excluded from data analysis.

Table 3: Multivariate associations between sociodemographic factors and the use of alcohol on the most recent incident of penetrative sex. 
is a significant link between students' consumption of alcohol and sexual intercourse. The study further shows a significant association between alcohol consumption on the previous event engaging in sexual intercourse with having many sexual partners. Findings also revealed a high number of students who frequently used alcohol were prone of not using condoms consistently with casual partners. Findings show a widespread practice of alcohol use in relation to sexual actions between both male and female students.

This study revealed that $32 \%$ of the total participants had multiple sexual partners. Approximately $40 \%$ of the male compared to $22 \%$ female students had multiple sexual partners in the previous six months. Despite the difference in the prevalence between male and female students, findings indicate that both male and female students were prone to engaging in multiple sexual partnerships after consuming alcohol. This finding is in agreement with the study conducted in all institutions of higher learning by the Higher Education and Training HIV/AIDS Programme [7]. Among students with multiple sexual partnerships some had multiple and concurrent sexual partnerships whereby they were involved in more than one sexual partnership as the same time. Multiple and concurrent sexual partners have been identified as likely drivers of the spread of HIV in countries with a generalised epidemic. Multiple and concurrent sexual partnerships are connected a "sexual network" which refers to anyone linked through a sexual relationship past or present; every partner one has ever had, and their entire past and present partner [6]. These concurrent sexual partnerships enable HIV to spread quickly especially in large sexual networks and the entire population can be affected. This view is supported by theoretical models predicting that increases in the prevalence of multiple and concurrent sexual partners increased the rate of the spread of the disease [9]. Multiple and concurrent sexual partners among students sometimes are engaged in with older or young sexual partners and some are transactional in nature [7]. Transactional sexual relationship put students at high risk of the HIV because older partners had been sexually active for a long time therefore the risk of being getting infected with HIV is higher compared to younger students.

This study associated seldom or frequent use of alcohol in the last six months with increased risk of engaging multiple and concurrent sexual partnerships. This finding confirms a study that reported that alcohol inhibited students' reason such that they found it easy to engage in casual sexual relationships [9]. The link between alcohol consumption, and engaging in sexual intercourse, and having multiple concurrent sexual partnerships that can be one after the other or simultaneous supporters supports the argument that the belief people have about the effects of alcohol, known in the field as alcohol expectancies, contributed to the decision to both consume and engage in certain sexual behaviour [7].

This study found significant evidence that students who frequently used alcohol in relations to engaging in sexual intercourse were at higher risk of not using condoms consistently with casual partners. This behaviour may be attributed to the personal trait of sensational seeking also called excitement seeking, a tendency where students pursue sexual pleasure and excitement for its own sake, and take risk in pursuit of such sexual experience. A study found that students who engaged in one type of risk behaviour were prone to indulging in other types [7]. This study is in agreement with studies that reported that male and female students who engage in sexual intercourse after using alcohol were likely to engage in unprotected sex $[11,18]$. Therefore, failure to use condoms consistently, engaging in multiple and concurrent sexual partnerships expose students to the risk of HIV infection. The study also found a link between coming from rural home areas to naivety to be easily persuaded to engage in unprotected sex with an off or on campuspartner. This can be attributed to sudden independence from parental monitoring students experience when they join university. In addition, literature review attributed the association between rural residence of students' childhood and inconsistent condom use to students" sudden exposure to both active and liberal urban settings [11,20,21]. Previous studies also show that relocating to an urban university setting such as Durban city from rural upbringing such as Nongoma in KwaZuluNatal influenced their sexual behaviour $[9,18]$.

\section{Limitation of the study}

There are two noteworthy limitations of this study: generalisability and causal effects. The generalisabilty of these research findings will be limited because they will be generated in one college in the university under study. This liability was clear at the outset. However, because the inquiry is intended to generate a relatively clear and specific understanding of the relationship between alcohol use and sexual risk behaviour among students at the College of Law and Management Studies, University of KwaZulu-Natal, it should be relatively easy to design a series of focused exploratory and descriptive studies at the university level to verify and expand the findings. These studies would be much more likely to produce findings generalisable to the university if conducted at the university level. As a retrospective survey, this study does not demonstrate causality, only an association between alcohol use and sexual risk behaviour among students.

\section{Recommendations}

It is critical that HIV prevention organisations and programmes; private and public address students belief about alcohol consumption because they influence students decision to use alcohol and eventually engage in high risk sexual behaviour.

HIV intervention programmes or organisations should take serious care of students' behaviour linking alcohol use to high sexual risk behaviour so that no excuse is given by students for engaging in unprotected sex.

It is high time HIV interventions paid attention to both male and female students in a pragmatic manner. HIV prevention messages should accentuate the risk of using alcohol in relations to casual sex a high risk sexual behaviour.

University policies should not only stop the availability of alcohol on campuses but should go as far as initiating programmes addressing many health issues including healthy use of alcohol.

\section{Conclusion}

This study reveals that alcohol consumption is linked to the practice of having many sexual partners and erratic use of condom with new partners. This phenomenon was common among students who often used alcohol in relation to engaging in penetrative sex. The relationship between alcohol use and sexual risk behaviour is complicated. The relationship seems to be instigated by several facets including biological, individual, behavioural, and socio-environmental factors. The argument the study is advancing is that HIV and AIDS prevention and awareness interventions targeting students need to address the influence of alcohol on sexual risk behaviour on campuses. HIV and AIDS prevention and awareness communication programmes should target students who consume alcohol in relation to engaging in penetrative sex. It is not enough to have a university policy that 
Citation: Given M (2014) An Exploratory Study of the Relationship between Alcohol Use and Sexual Risk Behaviour among Students at the University of Kwazulu-Natal. J AIDS Clin Res 6: 412. doi:10.4172/2155-6113.1000412

proscribes consumption of alcohol on campuses. Instead, measures should be put in place to translate the policy into practice to prevent the consumption of alcohol on South African university campuses.

\section{References}

1. UNAIDS (2015) Global Aids Response Progress 2014. Geneva, Switzerland.

2. UNICEF (2013) ANNUAL REPORT. UNICEF, Nepal.

3. Shisana O, Rehle T, Simbayi LC, Zuma K, Jooste S, et al. (2015) South African National HIV Prevalence, Incidence and Behaviour Survey, 2012. HSRC Press, Cape Town.

4. Department of Health (2013) Department of Health Annual Report 2012/13. Pretoria: South Africa.

5. UNAIDS (2012) UNAIDS Report on the Global AIDS Epidemic. UNAIDS Geneva.

6. Mutinta G, Govender K, Gow J, George G (2012) An exploratory study of the individual determinants of students sexual risk behaviour at a South African university. African Journal of AIDS Research 11: 353-359.

7. HEAIDS (2010) HIV Prevalence and Related Factors: Higher Education Sector Study, South Africa, 2008-2009. HEAIDS, Pretoria.

8. Pengpid S, Peltzer L, Skaal K (2013) Mental health and HIV sexual risk behaviour among University of Limpopo students. South African Journal of Psychiatry 19: 25-30.

9. Mutinta G (2012) Investigating Students' Sexual Risk Behaviour, Risk and Protective Factors and Their Responses to the Scrutinise Campus Campaign at Universities in KwaZulu-Natal. Unpublished doctoral thesis. Durban: University of KwaZulu-Natal.

10. WHO (2015) Global status report on alcohol and health 2014. World Health Organisation, Geneva.

11. Mogotsi M, Nel K, Basson, W and Tebele C (2015) Alcohol Use by Students at an Emerging University. South Africa Journal of Sociology Social and Anthropology 5: 187-195

12. Mulwo A (2009) An Analysis of Students' Responses to ABC and VCT Messages at three Universities in KwaZulu-Natal Province. PhD Thesis, Unpublished. Durban: University of KwaZulu-Natal.
13. Ham LS, Hope DA (2003) College students and problematic drinking: a review of the literature. Clin Psychol Rev 23: 719-759.

14. McKirnan DJ, Vanable PA, Ostrow DG, Hope B (2001) Expectancies of sexua "escape" and sexual risk among drug and alcohol-involved gay and bisexual men. J Subst Abuse 13: 137-154.

15. Ketoja J, Svidkovski AS, Heinälä P, Seppä K (2013) Risky drinking and its detection among medical students. Addict Behav 38: 2115-2118.

16. Fang CY (2008) The moderating effect of impression management on the organizational politics performance relationship. Journal of Business Ethics 79:12-25.

17. Harder JW (1991) Equity theory versus expectancy theory: The case of major league baseball free agents. Journal of Applied Psychology 76: 458-464.

18. Maponyane ES (2012) University of Limpopo (Medunsa Campus) Psychology Undergraduate Students' Knowledge, Attitudes, Behaviours and Beliefs Regarding HIV and AIDS. Masters Dissertation, Unpublished. Garankuwa: University of Limpopo (Medunsa Campus).

19. Steele CM, Josephs RA (1990) Alcohol myopia. Its prized and dangerous effects. Am Psychol 45: 921-933.

20. Burrell E, Mark D, Grant R, Wood R, Bekker LG (2010) Sexual risk behaviours and HIV-1 prevalence among urban men who have sex with men in Cape Town, South Africa. Sex Health 7: 149-153.

21. Lane T, Raymond HF, Dladla S, Rasethe J, Struthers H, et al. (2011) High HIV prevalence among men who have sex with men in Soweto, South Africa: results from the Soweto Men's Study. AIDS Behav 15: 626-634.

22. Ramsoomar L, Morojele NK (2012) Trends in alcohol prevalence, age of initiation and association with alcohol-related harm among South African youth: implications for policy. S Afr Med J 102: 609-612.

23. WHO and UNICEF (2013) Global Aids Response Progress Reporting. Geneva: UNAIDS.

24. Pithey AL, Morojele NK (2002) Review on Alcohol Use and Sexual Risk Behaviour in South Africa. Pretoria: Alcohol and Drug Abuse Research Unit Medical Research Council.

25. Miner JB (2005) Organizational behaviour: Essential theories of motivation and leadership. ME Sharpe, Armonk, NY. 